\title{
Empirical base solar reflective array accumulator design simulator
}

\author{
Budhy Setiawan ${ }^{1, *}$, Riska Nur Wakidah ${ }^{1}$, Raden Edy $\mathrm{P}^{2}$, Annisa Maulidia $\mathrm{D}^{1}$, Yulianto Yulianto ${ }^{1}$, and Widjanarko \\ Widjanarko ${ }^{2}$
}

${ }^{1}$ Malang State Polytechnic, Electrical Engineering Department, Malang, Indonesia

${ }^{2}$ Malang State Polytechnic, Mechanical Engineering Department, Malang, Indonesia

\begin{abstract}
Sun energy in Indonesia is $5 \mathrm{Kwh} / \mathrm{m}^{2} /$ day average per year. This alternative energy can be convert to solar thermal up to $80 \%$ efficiency, the percentage is highly significant compare to electric conversion that only has $20 \%$. To provide any process requirement for heating, an empirical research of reflective array accumulator has been done, so that a design simulation for the accumulator has to be held. The accumulator can be used as a heat energy supplier for drying, egg hatching, food oven and other requirement. The sun energy trapping method is a reflective array. This method aims to maximize the energy captured and stored in an accumulator and has to be maintained for 24 hours by opening and closing the array. This simulator will calculated and control some input such as water mass, accumulator temperature, environment temperature, humidity and sun intensity. The array control performance to watch diffuse solar light intensity by time. The result of the simulation will give absorption storage capability, insulation capability to watch sun energy performance per day. It is expected that with the simulation, it can simplify the design of the accumulator and improve the efficiency of heat energy storage. The absorption capability perform $72 \%$.
\end{abstract}

\section{Introduction}

Since 2008 world fossil reserve was decreased and predicted will be exhausted in 2020 [1,2,3]. One of the solutions for this problems is renewable energy that utilization a solar energy. Solar energy utilization is very wise in providing electrical energy because it is free and lasting $[1,2,4]$. On a tropical surface of the earth, solar energy has an energy up to $7 \mathrm{KWh} / \mathrm{m}^{2} /$ day average per year [5]. Generally, solar energy technologies are converted to electric. However, it is also can convert to thermal energy and stored by dry or wet storage media [6].

Solar thermal energy storage can be used on accumulator by converting the solar radiation to heat and transmitting it to water transfer media [7]. Converting the solar radiation to heat are wise technologies because it has an efficiency up to $80 \%$ on energy conversion $[6,8]$, compared to a solar cell that only has a maximum converting $20 \%$ solar energy [9].

Solar thermal energy storage technologies are wise and effectively used in Indonesia. Because, Indonesian geographical position in the tropical coordinate and has a high solar energy, $5 \mathrm{KWh} / \mathrm{m}^{2} /$ day average per year [10].

With this energy capability, $5 \mathrm{KWh} / \mathrm{m}^{2} /$ day efficiency of collection and storage heat energy is $70 \%$ [11] (when using the method of collection and storage of the heat) [8].

\footnotetext{
*Corresponding author: riska_nur@polinema.ac.id
}

Solar thermal energy storage by Kuye has a thermo siphon method. The principle of thermo siphon method is after water gets the heat from the sunlight collector, it will flow into an isolated tank, which is higher than the collector. The system has a low energy efficient storage, $40 \%$. The low efficiency is caused by solar thermal energy must be converted to water thermal energy and physically transferred from the collector to the water tank above it. Upward movement means a loss of energy in the form of pressure. In addition, the amount of energy that become vapor pressure will cause overpressure [12]. In this research, the solar thermal energy stored in accumulator, and the heat storage material is waters. Flat collectors principle to be utilized in this system that have efficiency up to $70 \%$ $[11,12,13,14]$. In addition, to optimized the energy that was absorbed, reflective array method used. In the conventional SWH (solar water heater), the energy that was absorbed will be leak out at the night and the energy will be exhausted faster [14].

This research is expected to reduce the use of electrical energy on use of the requirement that needs a heat directly like an egg hatching, food oven, drying process, and etc.

\section{Empirical method}

Solar reflective array accumulator is set up as Fig. 1. The solar reflective accumulator is an insulated vessel and 
high reflectivity that can store and keep solar thermal energy with water media in vessels of galvanized bars.

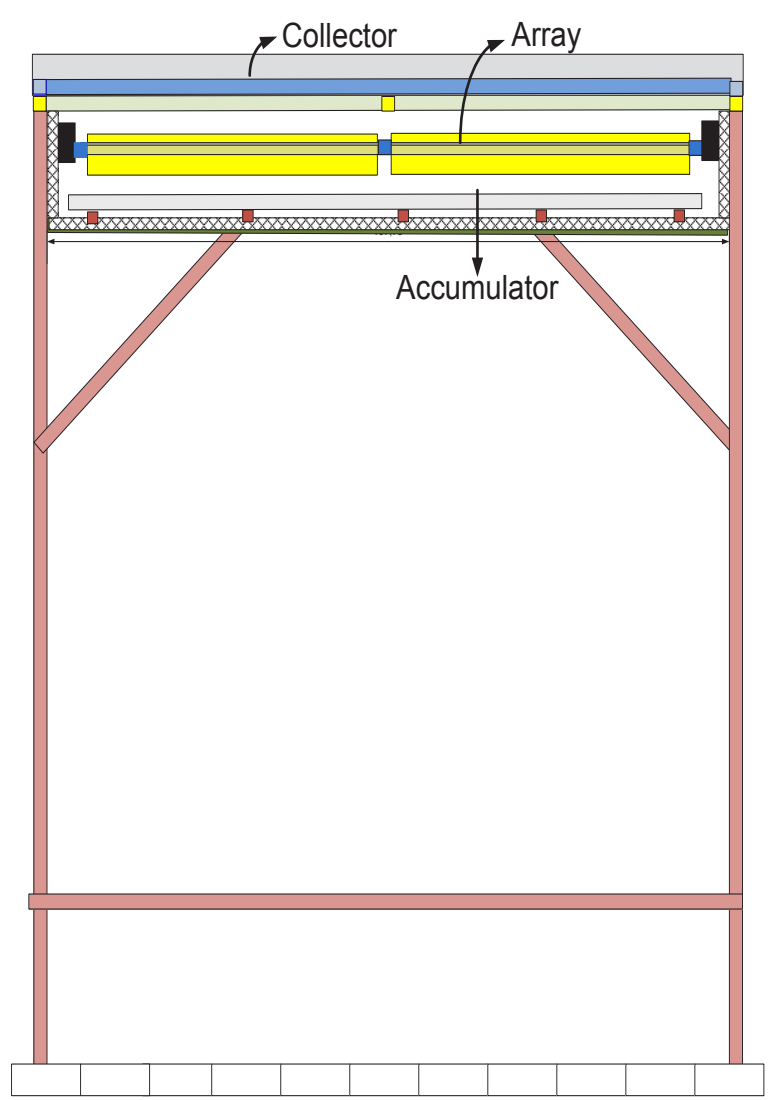

Fig. 1. Solar Reflective Array Accumulator

\subsection{Flat collector principle}

Flat collector principles are simplest and commonly used for converting the sun's radiation into useful heat. They are designed for applications requiring heat energy to temperature [14].

In Fig. 2 show that with a flat collector, the accumulator absorbs diffuse solar thermal energy.

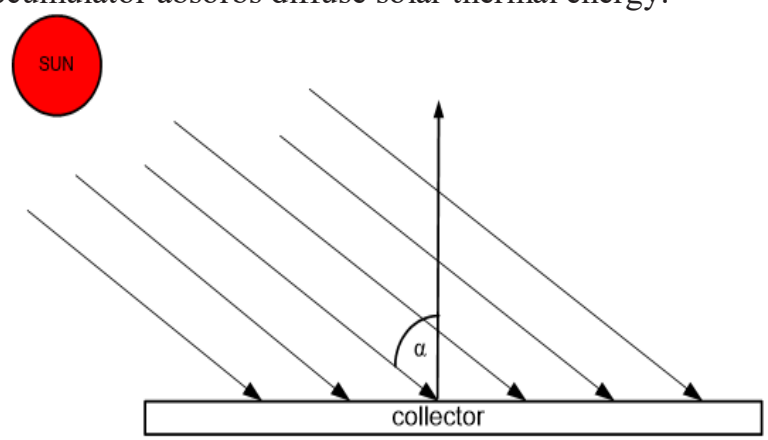

Fig. 2 Flat Collector Principle.

The flat accumulator can absorb the solar thermal energy such as this equation [kuye]:

$$
\begin{aligned}
& E_{\text {diff }}=\int_{t_{0}}^{t} P_{\text {diff }} d t \\
& P_{\text {diff }}=P_{\text {sun }} \cdot \cos \theta
\end{aligned}
$$

$$
P_{\text {sun }}=I_{\text {sun }} / 100
$$

$E_{\text {diff }}=$ Diffuse Energy (Watt-hours)

$P_{\text {diff }}=$ Diffuse Power (Watt)

$P_{\text {sun }}=$ Sun Power (Watt)

$I_{\text {sun }}=$ Sun Intensity (Lux)

$\theta \quad=$ Angle between sunlight direction and zenith angle

In addition, the efficiency of the flat collector expression of equation (4):

$$
\begin{aligned}
\eta_{\text {diff }}= & \frac{E_{\text {diff }}}{E_{\text {Sun }}} .100 \% \\
= & \frac{\int_{t 0}^{t} P_{d i f f} d t}{\int_{t 0}^{t} P_{\text {sun }} d t} .100 \%
\end{aligned}
$$

\subsection{Arrays control optimizer}

Control linear mirror arrays are performed on the array movement in order to keep the heat energy that has been stored.

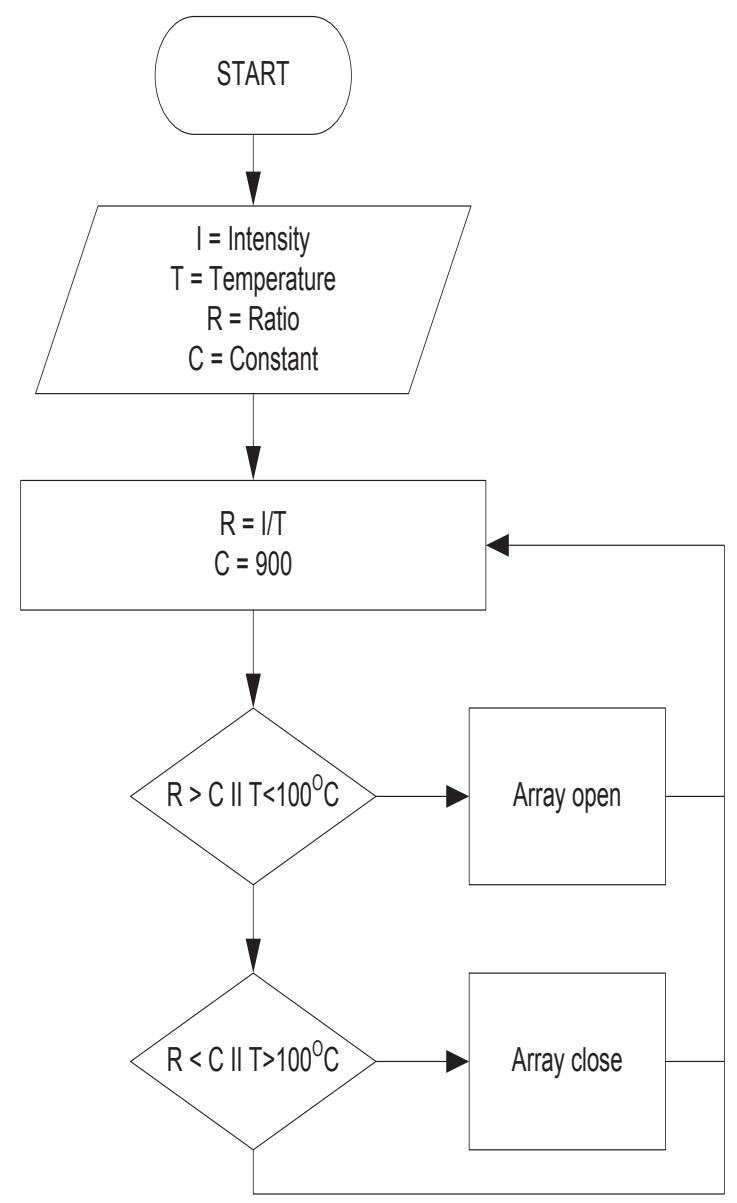

Fig. 3 Control linear mirror array. 
From Fig. 3 shown that the array will be opened if the ratio more than the constant or the temperature less than $100^{\circ} \mathrm{C}$. In addition, the array will be closed if the ratio less than the constant or the temperature more than $100^{\circ} \mathrm{C}$.

The constant is the ratio between intensity and temperature. If the ratio is more than 900 then indicates that the intensity at that time is high and the accumulator will absorb solar thermal energy. In addition, if a ratio of less than 900 indicates that the intensity is low and the array must be closed to keep the heat energy absorbed. If the array always opened, the energy in the accumulator will come out and exhausted. The constant value obtained from experiments that have been done. The value is an effective value that can be used to maintain energy in the accumulator.

The temperature on the accumulator is maintained to be no more than $100^{\circ} \mathrm{C}$, if the temperature is more than $100^{\circ} \mathrm{C}$ the array will close. It serves to keep the pressure in the galvanized bar and mechanical accumulator.

\subsection{Thermal energy storage capability}

Energy storage capability is directly influenced by two components, namely mass and specific heat capacity. As an expression of equation (5).

$$
E=\int_{T 0}^{T_{1}} m c d T
$$

$E=$ Saved energy (Joules)

$m=$ Mass of the material $(\mathrm{Kg})$

$c=$ Specific heat capacity of the material $\left(\mathrm{J} / \mathrm{g} /{ }^{\mathrm{O}} \mathrm{K}\right)$

$T=$ Temperature $\left({ }^{\mathrm{O}} \mathrm{C}\right)$

On the research, thermal energy storage using water media. The specific heat capacity of water is $4.2 \mathrm{~J} / \mathrm{g} /{ }^{\mathrm{O}} \mathrm{K}$. The energy that can be stored will be higher if the specific heat capacity higher.

\section{Result and discussion}

\subsection{Simulation method}

On 12-13 and 14-15 the experiment was held at State Polytechnic of Malang, Malang city, East Java, Indonesia. Coordinates $7^{\circ}$ 56' 44.57" south and the latitude; $112^{\circ} 36.53 .20^{\prime \prime}$ east longitude and is at an altitude of $499 \mathrm{~m}$ above sea level. Fig. 4 is based on empirical data that recorded by DAQ (Data Acquisition Interface) and simulation.

In the experiment, the collector area used $3.14 \mathrm{~m}^{2}$ with absorption efficiency of $68 \%$. The efficiency is obtained without using linear mirror array control, the array will close when the temperature reaches $100^{\circ} \mathrm{C}$. The average energy loss is $0.28 \mathrm{KWh} / \mathrm{h}$. To simplify improve system, simulation design based on empirical data has to be held that shown in Fig. 5 .

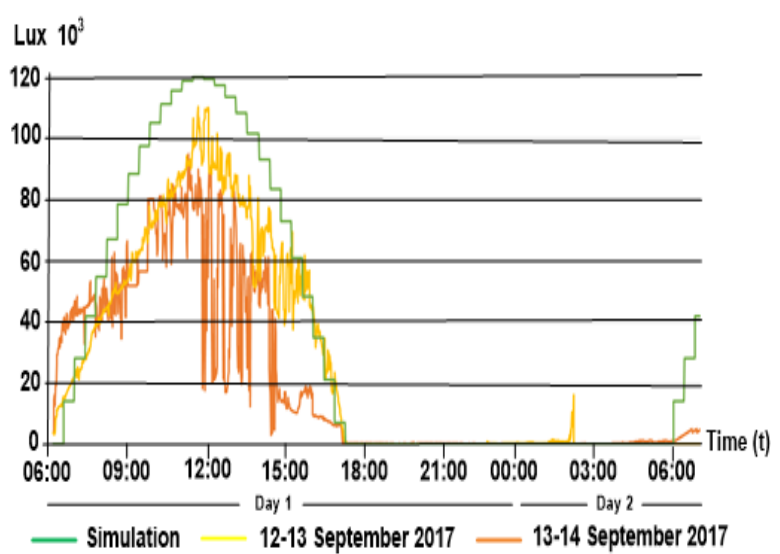

Fig. 4 Solar Intensity.

This simulation is to improve on the intensity of sunlight, water mass (storage media) and load. In addition, simulations are performed to show the direct effects on energy and temperature, also the absorption efficiency if the parameter was being improved.

In Fig. 5 shows a few blocks of the process. Block collector starts from the intensity of the sun received and then convert to the power of the sun as shows in equation (3). The value of intensity on empirical data received shows the value of each $1 \mathrm{~m}^{2}$, then $P_{c}$ (Power of collector) should be multiplied by the area of the collector and the absorption efficiency.

The output from the simulation shows the energy that was absorbed by the accumulator $\left(E_{a c c}\right)$ and the accumulator temperature $(\mathrm{T})$.

The accumulator energy is derived from the integral power of collector as shown in equation (1). In Fig. 5 the energy absorption process is shown in blocks of charging process. The absorbed energy is expected to be maintained at night, so the linear mirror array control used that has been discussed in point 2.2. In linear control mirror array block indicates the working system, when $C>900$ the charging system runs to absorb the energy and when $C<900$ the array will close to preserve the absorbed energy and the running process discharge.

Temperature calculation of accumulator derived from the decreasing of equation (5). The temperature value is effected by the mass of the storage media, the specific heat capacity of the material and the energy at that moment which is directly influenced by the light intensity. The temperature on the accumulator is maintained not to exceed $100^{\circ} \mathrm{C}$ to keep the galvanized bar pressure and the accumulator mechanics that has been discussed in point 2.2.

By using simulation design, we can find out the direct influence that will occur if done improve system parameters has been carried out. So, hopefully with the simulation done will make it easier to improve and can increase the efficiency of the system. 


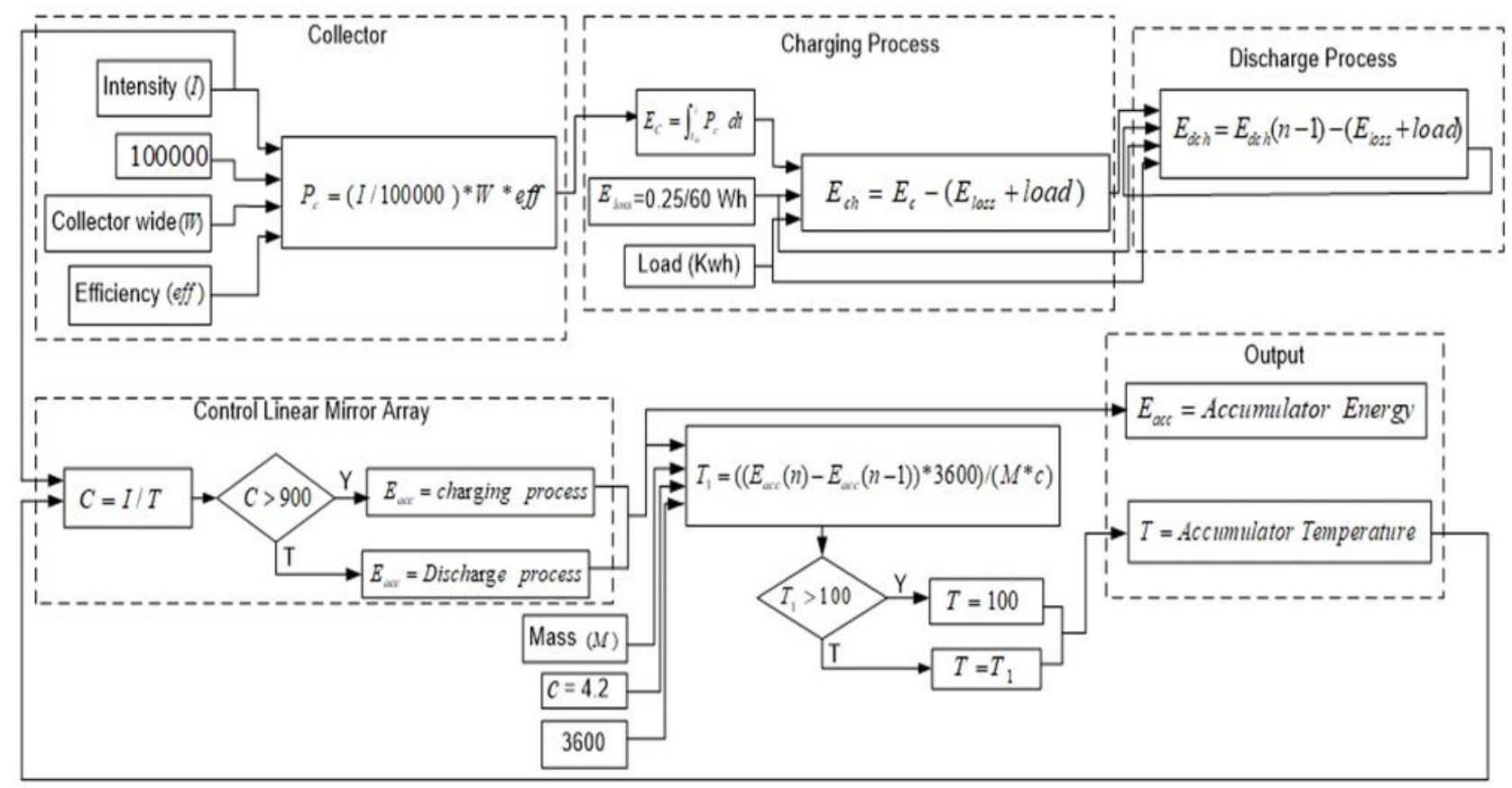

Fig. 5 Simulation block.

\subsection{Result}

Fig. 4 shown that on 12-13 Sept. 2017 have a great intensity with peak intensity are 110.000 lux at 11:57. And then, on 14-15 Sept. 2017, the intensity relatively fluctuate with peak intensity is 90.000 lux at 11:40. Simulation signals illustrate the solar cycle that at 06:00 the sun will rise and at 18:00 the sun will disappear with peak intensity 120.000 lux at 12:00.

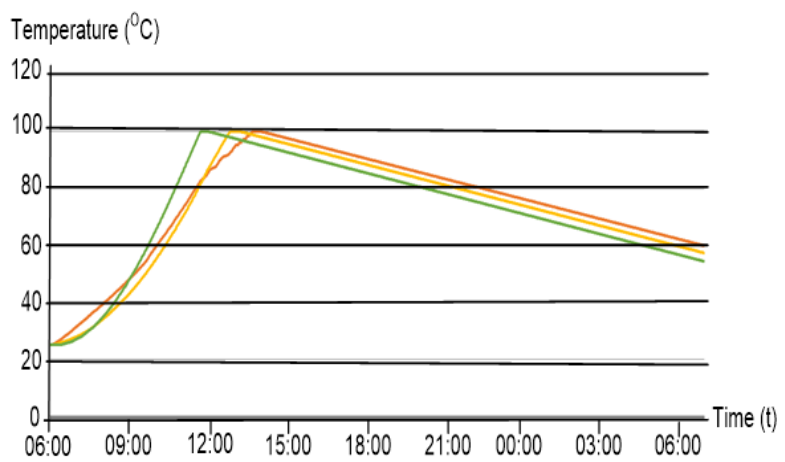

Fig. 6 The accumulator temperature.

In Fig. 6 it looks that with high intensity the temperature will be rise faster. Its look like the simulation data, the maximum temperature reached in 5 hours. In addition, with fluctuate intensity (14-15 Sept.) the maximum temperature reached in 8 hours. From empirical data that was held, the average of losing temperature are $2.5^{\circ} \mathrm{C} / \mathrm{h}$. losing temperature can be caused by several factors, such as an insulation material, design, and the vacuum glass collector.

Then the simulation improved with the same intensity and different mass of water.

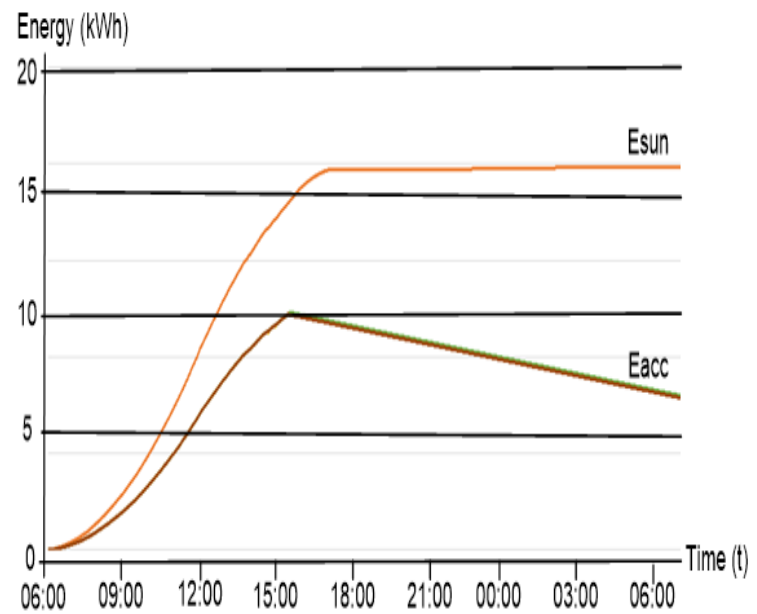

Fig. 7 Efficiency of accumulator.

Fig. 7 shown, with the same intensity the energy that was absorbed will be same. The energy that can be trapped in the accumulator is affected by the accumulator's efficiency. So, from Fig. 6 can be calculated the efficiency of the accumulator that expressed on equation (6).

$$
\eta_{\text {diff }}=\frac{E_{\text {diff }}}{E_{\text {Sun }}} .100 \%
$$

From this equation, it can be seen that the solar reflective array accumulator method has an efficiency absorb $72 \%$. 


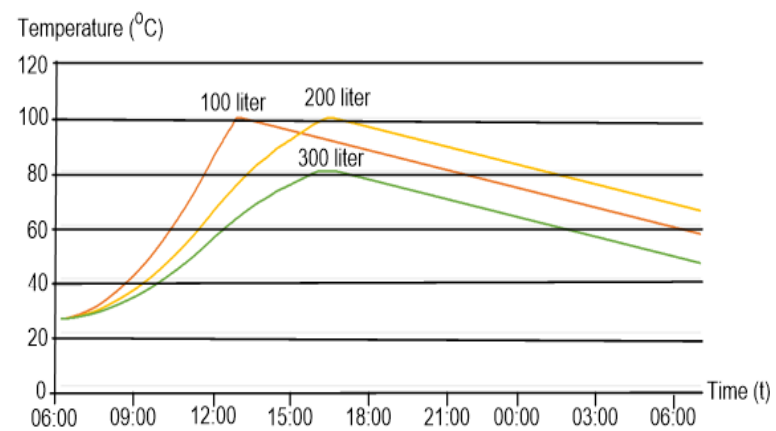

Fig. 8. Accumulator temperature with water mass improve.

Fig. 8 shows the accumulator temperature with water mass improved. Its shows that the water mass can affect the accumulator's time to reach the highest temperature. Using 100 liters of water the highest temperature can be reached within 6 hours 47 minutes at 12:47. While using 200 liters of water the highest temperature is reached more slowly i.e. 11 hours at 17:00. And by using 300 liters of water the temperature never reached $100^{\circ} \mathrm{C}$, the highest temperature reached only $80^{\circ} \mathrm{C}$.

The simulation improved with different load show in Fig. 9.

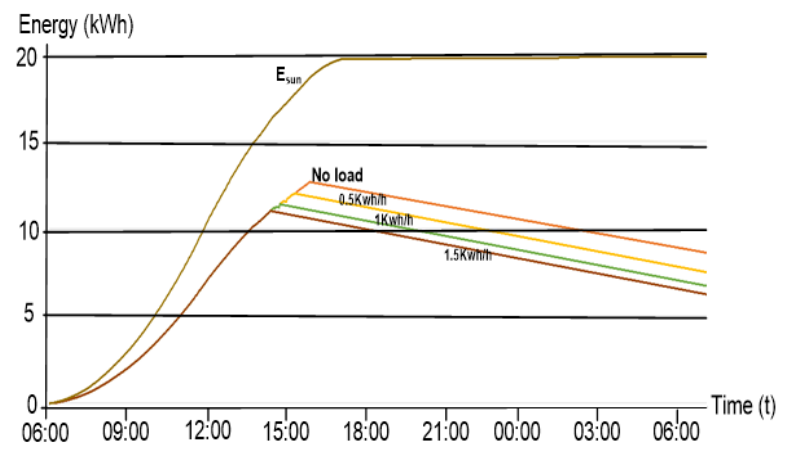

Fig. 9. Accumulator energy with load improved.

Fig. 9 shows that the larger of the load given, the absorption efficiency will be getting smaller, it is due to the energy consumption. And the greater of the load, the energy that has been stored will more quickly run out.

The absorption efficiency shows at the Table 1 below:

Table 1. The absorption efficiency.

\begin{tabular}{|c|c|c|}
\hline Control & Load & Efficiency \\
\hline Without control & Without load & $68 \%$ \\
\hline With control & Without load & $72 \%$ \\
\hline With control & $0.5 \mathrm{KWh} / \mathrm{h}$ & $67 \%$ \\
\hline With control & $1 \mathrm{KWh} / \mathrm{h}$ & $64 \%$ \\
\hline With control & $1.5 \mathrm{KWh} / \mathrm{h}$ & $61 \%$ \\
\hline
\end{tabular}

Table 1 shown that the absorption efficiency with control is larger than without control. It is shown that the control is optimal. And the absorption efficiency is inversely proportional to the load, if the load is greater, then the absorption efficiency will be smaller. It is because the consumption of the load.

Fig. 10 show that the larger the load can also effect the temperature in the accumulator. The greater of the load, the maximum temperature will be achieved longer and the temperature will decrease more quickly.

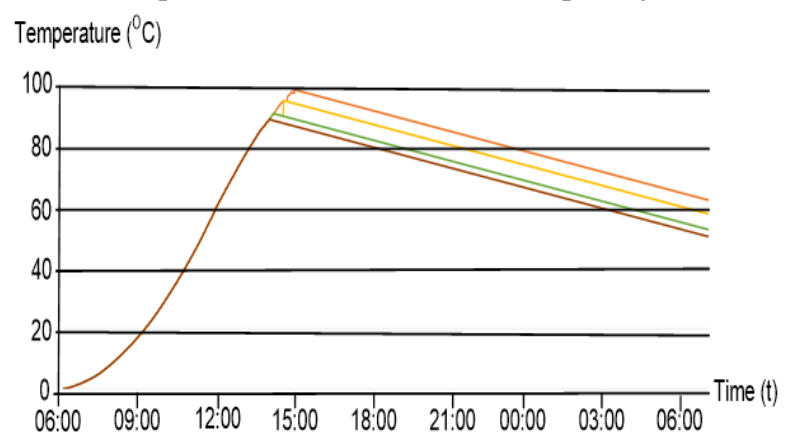

Fig. 10. Accumulator temperature with load improved.

\section{Conclusions}

From the simulation result, the solar reflective array accumulator method has an effective solar energy absorbed. The efficiency of solar energy absorbed in accumulator is $72 \%$. If the water has improved, time to the temperature rise are longer and the energy that absorbs most same. The larger the load given, the absorption efficiency will be getting smaller, it is due to the energy consumption. And the greater of the load, the energy that has been stored will more quickly run out.

\section{References}

1. Syah, Bastaman. Design of Temperature and Humidity Control System of hatcher-Based PLC (Programmable Logic Controller). Electrician Vol.2, no. 1, pp. 25-32,(2012)

2. B. Setiawan., M. H. Purnomo, M. Ashari, \& T. Hiyama, Advanced control of on-ship solar tracker using adaptive wide range ANFIS. Int. J. of Innovative Computing, Information and Control, Vol. 9, no.6, pp. 2585-2896, (2013).

3. B. Setiawan. Heat Regulator for Hybrid Hatch Machine with Buck PID Method. SENTIA 2017, Vol. 79, no.3, (2017).

4. B. Setiawan, H. Mauridhi, \& A. Mochamad, High Precision Angle Compensation Controller for Dish Solar Tracker Installed on a Moving Large Ship. Int. Review of Automatic Control (IREACO), Vol.6, No.6,pp 695-700, (2013).

5. A. L. Thomas, A. Becker, and R. J. Crawford, An Energy-Efficient Solar-Heated Greenhouse, Produces Cool-Season Vegetables all Winter Long, University of Missouri-Columbia, Community Food Systems and Sustainable Agriculture, Southwest Research Center, Mt. Vernon, Missouri 
6. M. N Nasruddin. Determination of Temperature in Egg Hatching Based on Microprocessor. J. of MIPA, vol.1, pp 30-33, (2007)

7. Ramli, M. Badli, et al. Egg hatching incubator using conveyor rotation system. Procedia Manufacturing Vol.2, pp 527-531, (2007)

8. B.Setiawan, Wirawan, H.Hariadi, Solar heat accumulator control applying reflective arraymethod foe energy optimization, ARPN Journal of Engineering and Applied Sciences, vol.13, No. 4 pp.1236- 1242 (2018)

9. B. Setiawan. Study of Energy Capacity of Solar Heat Accumulator for egg hatching machine. SENTIA vol. 7, no.1 (2015)

10. Republika, Indonesia Electricity Production Still Rely on Fossil Energy", interview with Minister of Energy and Mineral Resources Susilo Siswoutomo. $2020125 \mathrm{MW}$ currently $50 \mathrm{MW}$, coal as the backbone of electric energy other than fuel, 01 oktober (2014)

11. E. Ataer. Storage of Thermal Energy, in Energy Storage Systems, [Ed. Yalcin Abdullah Gogus], in Encyclopedia of Life Support Systems (EOLSS), Developed under the Auspices of the UNESCO, (Eolss Publishers, Oxford, UK., 2006)

12. Kuye, S. I., Adekunle, N. O., Adetunji, O. R., \& Olaleye, D. O, Design and Construction of Solar Incubator, College of Natural Sciences Proceedings, pp. 87-96. (2008)

13. B. Harits, L.Rozaqi, B. Setiawan, Design and building $1 \mathrm{~m}^{2}$ heataccumulator, Malang state Polytechnic's Student Final Report, (2013)

14. S. N. Agbo, and E. C. Okoroigwe. Analysis of thermal losses in the flat-plate collector of a Thermosyphon Solar water Heater. Research J. of physics, Vol. 1, no.1, pp. 35-41, (2007) 